\title{
CONFERÊNCIA
}

\section{FORMAÇÃO DE PROFESSORES DE CIÊNCIAS: velhos e novos modelos}

Elizabeth Antonia Leonel de Moraes Martines²

\section{INTRODUÇÃO}

Num momento em que a sociedade capitalista tenta reverter uma crise com a globalização e uma política neoliberal, num mundo cada vez mais dividido, a ciência moderna e as instituições que se desenvolveram apoiadas no paradigma científico da modernidade enfrentam crises desestabilizadoras que favorecem a emergência de novos modelos como alternativas para a superação dessas crises.

Por sua vez, o campo do currículo surgiv e se consolidou no Século XX, assim como a Psicologia, uma ciência jovem e abrigando uma multiplicidade de escolas (ou matrizes disciplinares), a qual vem influenciando modelos e práticas curriculares ao longo de todo o século XX, perdendo um pouco de prestígio nas últimas décadas com a ascendência da sociologia e da antropologia. Todas estas transformações afetam as instituições ligadas à produção e disseminação do conhecimento, possuindo profundas implicações para as universidades, especialmente quanto à formação de professores de um modo geral, porém, mais particularmente, para a área de ensino de ciências.

I Conferência proferida no II Seminário de Divulgação Científica do Laboratório de Ensino de Ciências (EDUCIENCIA) da Universidade Federal de Rondônia (UNIR) em Porto Velho / RO no dia $21 / 06 / 2016$.

2 Professora do Departamento de Biologia / UNIR, graduada em Licenciatura em Ciências e Biologia (UNESP), com mestrado e doutorado em Psicologia Escolar e do Desenvolvimento Humano pela USP; Líder do Grupo de pesquisa EDUCIENCIA da UNIR. E-mail: bethmartines@gmail.com 
Nesta conferência, fazemos uma reflexão diante da necessidade de se melhorar a qualidade da escola pública nos países periféricos, um desafio para a Universidade, especialmente as públicas, para o desenvolvimento de reflexões e ações envolvendo os/as professores/as dos vários níveis de ensino: formadores das licenciaturas e professores/as da educação básica em processos de formação continuada, alunos/as de cursos de formação inicial nas licenciaturas ligadas à área de ensino de ciências, gestores, políticos, entre outros.

Assim, tentarei mostrar as relações que se estabelecem entre cada momento histórico, especialmente com o desenvolvimento das ciências, e os modelos de formação de professores, as principais características da identidade docente e os currículos.

\section{MODELOS DE FORMAÇÃO DE PROFESSORES: principais características e consequências}

Segundo Bruner (1985), a construção da identidade dos professores seguiu modelos que apresentam características da docência nos diferentes momentos históricos, a saber: a identidade missionária, evangelizadora ou apostólica, o professor funcionário, o professor técnico, o professor trabalhador da educação e o professor profissional. Semelhantemente, Ramalho, Nuñez e Gauthier (2004) propõem quatro modelos de professor: o professor improvisado, o professor artesão, o professor científico e o professor profissional.

Outros autores (NÓVOA, 1995; PERRENOUD, 2001; PIMENTA; ANASTASIOU, 2002; PEREIRA; ZEICHNER, 2002; MARTINES, 2005; HUBERMAN, 1995 entre outros) também têm se dedicado ao estudo do tema e discutem modelos que se relacionam com a identidade docente ou com as características de sua formação e suas influências no currículo, na organização escolar, na avaliação, entre outras.

O Quadro 1 sintetiza o conteúdo desta palestra, contendo síntese e reflexões desenvolvidas ao longo das últimas décadas dentro do grupo de 
pesquisa Laboratório de Ensino de Ciências da UNIR (EDUCIENCIA), sendo que os modelos apresentados se relacionam com a construção da docência no ocidente, relacionados com a história da escola, os paradigmas científicos da história das ciências, as representações da sociedade e dos próprios docentes e suas organizações representativas (associações, sindicatos etc.) (MARTINES, 2005; 2008; 2010; 2014).

Quadro 1- Modelos formativos, principais características e consequências

\begin{tabular}{|c|c|}
\hline $\begin{array}{l}\text { Período histórico / } \\
\text { Modelos formativos }\end{array}$ & $\begin{array}{l}\text { Características principais e consequências na escolarização e } \\
\text { formação de professores }\end{array}$ \\
\hline $\begin{array}{l}\text { Período } \\
\text { clássico/religioso } \\
\text { (Século IV a. C. - } \\
\text { Século XVII) }\end{array}$ & $\begin{array}{l}\text { Não havia formação de professores: para ser um mestre basta } \\
\text { (va) ser versado em algum saber; o professor improvisado, o } \\
\text { professor artesão, identidade missionária, evangelizadora ou } \\
\text { apostólica. }\end{array}$ \\
\hline Período moderno & $\begin{array}{l}\text { Criação dos sistemas escolares nacionais gera necessidade de } \\
\text { formação de professores }\end{array}$ \\
\hline $\begin{array}{l}\text { Racionalismo } \\
\text { acadêmico } \\
\text { (início no Século XIX } \\
\text { até hoje) }\end{array}$ & $\begin{array}{l}\text { Formação segundo currículo tradicional: currículo baseado em } \\
\text { conteúdos das disciplinas acadêmicas, na avaliação por } \\
\text { exames feitos por examinadores externos à escola e } \\
\text { organização do alunado em salas de aulas; modelo de } \\
\text { instituiçáo escolar - jesuítico. Identidade: o professor } \\
\text { funcionário. }\end{array}$ \\
\hline $\begin{array}{l}\text { Racionalismo técnico } \\
\text { (meados do Século XX } \\
\text { até hoje) }\end{array}$ & $\begin{array}{l}\text { Modelo } 3+1 \text { voltado para formação do professor funcionário } \\
\text { acrescido de conhecimento técnico-científico. Currículo por } \\
\text { objetivos: prescritivo e técnico-linear. }\end{array}$ \\
\hline $\begin{array}{l}\text { Racionalismo crítico e } \\
\text { pós-crítico (1970-atual) }\end{array}$ & $\begin{array}{l}\text { Foco na transformação da sociedade: teoria marxista e } \\
\text { neomarxista com propostas que vão da desescolarização à } \\
\text { desconstrução do conhecimento escolar e científico. } \\
\text { Pedagogia libertadora: currículos alternativos. Identidade } \\
\text { docente: o professor trabalhador da educação. }\end{array}$ \\
\hline $\begin{array}{l}\text { Racionalismo prático } \\
\text { (Décadas 1970-1980) }\end{array}$ & $\begin{array}{l}\text { Identidade docente: Professor como artesão - Bricolagem } \\
\text { e/ou Professor pesquisador e pesquisa-ação; Foco na prática } \\
\text { do professor: professor reflexivo. Currículo tradicional ou } \\
\text { aperfeiçoamento de currículos alternativos com } \\
\text { desenvolvimento profissional do professor. }\end{array}$ \\
\hline $\begin{array}{c}\text { Modelo emergente } \\
\text { (a partir da década } \\
\text { de 1990) }\end{array}$ & $\begin{array}{l}\text { Profissionalização do Professor; Currículo como processo social: } \\
\text { Currículo como ponte entre a teoria e a prática; lócus de } \\
\text { formação - a escola, pesquisa-ação participativa ou } \\
\text { colaborativa; estágio de docência com pesquisa-ação. } \\
\text { Identidade docente: o professor profissional prático-reflexivo. }\end{array}$ \\
\hline
\end{tabular}

Fonte: Elaborado pela autora. 
A seguir, faremos comentários sobre cada um destes modelos, suas características e principais implicações no currículo de diferentes níveis escolares.

\subsection{Modelo clássico-religioso}

Durante mais ou menos vinte séculos (desde a Grécia antiga até século XV) predominou no ocidente uma concepção de ciência chamada modelo aristotélico/religioso, baseado na reflexão filosófica e na teologia escolástica que se desenvolveu no final da Idade Média, com forte influência dos filósofos do período clássico grego. Este modelo vai ser lentamente substituído pelo que hoje conhecemos como ciência moderna, a partir do Século XVI, a qual foi impulsionada por diferentes eventos como: descoberta de novas terras a partir das grandes navegações, invenção da imprensa, a Reforma Protestante, a revolução industrial, perda ou diminuição de poder pela nobreza e ascensão da burguesia, entre outros (MARTINES, 2000).

O ensino era feito por pessoas instruídas em algum ofício, arte, filosofia ou religião, com um mestre ensinando um ou poucos aprendizes que recebiam instruções verbais e treinamento de habilidades, tendo o mestre como modelo a ser seguido. Não havia formação de professores: para a docência basta ( $\mathrm{va}$ ) ser versado em algum saber. Na verdade, até hoje encontramos este modelo em várias áreas, até mesmo no ensino formal, especialmente em regiões brasileiras mais isoladas, nas quais encontramos frequentemente: o "professor improvisado", o "professor artesão" ou com identidade missionária, evangelizadora ou apostólica (docência como dom, por amor e caridade) (BRUNER, 1985; NÓVOA, 1995; RAMALHO; NUÑEZ; GAUTHIER, 2004).

A longa história desta tradição consolidou um tipo de instituição baseada no "modelo jesuítico" (PIMENTA; ANASTASIOU, 2002) no qual a formação e a personalidade de cada professor são elementos fundamentais para a eficácia do método de ensino e cabe ao docente acompanhar 
cada aluno, adaptando-se a ele e pondo em jogo todo o seu saber, solicitude e amor e concentrando toda a sua ciência em saber ensinar. As normas tinham (têm) que ser rigidamente seguidas e não havia currículo sistematizado nem avaliação formal.

Goodson (1995) afirma que foi neste contexto, no início do século XVI, que o termo currículo relacionado à escolarização foi usado pela primeira vez em 1509, em Paris quando o College of Montaign instituiu o conceito de "[...] classes de trabalho, isto é, divisões graduadas por estágios ou níveis de complexidade crescente, de acordo com a idade e o conhecimento exigido dos alunos" o que levou à prescrição de conteúdos para cada nível, constituindo um curso (caminho) ou plano a ser seguido (MARTINES, 2005, p. 51). Inicia-se a transição do ensino individualizado do mestre com seu discípulo para um ensino simultâneo destinado a um grupo mais ou menos homogêneo de estudantes.

A este conceito do currículo escolarizado associado à classe e prescrição de conteúdos, no século XVII vem acrescentar-se o de disciplina. Este conceito adquire duas conotações: enquanto ordem estrutural relaciona-se com o conteúdo disciplinar que vai se firmando no âmbito das ciências, mas também tem um significado relacionado com seu caráter disciplinador, de auto-controle, introduzido pelos reformadores protestantes.

Com a consolidação da ciência moderna nos séculos seguintes, acompanhada da expansão da imprensa e fortalecimento da burguesia, a necessidade de educação de uma massa crescente de crianças e jovens oriundas das classes trabalhadoras e burguesas cria uma demanda social por escola nos países industriais capitalistas da Europa e da América, levando à criação dos sistemas escolares nacionais pelos governos de várias nações-estado (PATTO, 1996; MARTINES, 2001; 2005). Com isto, inaugura-se a preocupação com a necessidade de formação de professores para dar conta desta demanda. 


\subsection{0 modelo do racionalismo acadêmico}

Com a emergência dos sistemas nacionais de educação que surgiram no período do lluminismo por influência da filosofia liberal da burguesia emergente, as classes foram transformadas em salas de aula para atender um número maior de alunos; os currículos foram sendo diferenciados de acordo com a clientela.

Assim, ao longo do Século XIX foi se consolidando o que ficou conhecido como currículo tradicional que se refere a um plano organizado sequencialmente ao longo da escolarização, graduado em nível de profundidade crescente, sendo que cada etapa tem que ser rigorosamente cumprida antes de se passar para a seguinte. Esta organização linear e em cadeia do conhecimento ainda é diferenciada de acordo com o grupo de alunos a que se destina (alunos de zona rural, urbana, classe trabalhadora ou classe média), portanto, se torna uma organização também diferenciadora, acentuando as diferenças sociais.

O resultado foi a consolidação de um modelo de instituição escolar conhecido como modelo jesúítico, no qual o currículo acadêmico se organiza em unidades hierárquicas, "[...] na divisão e graduação das classes e programas em extensão e dificuldade, não se permitindo passar a uma etapa mais avançada sem que a anterior estivesse totalmente dominada" (PIMENTA; ANASTASIOU, 2002, p. 146).

O conhecimento presente no currículo (plano de curso) é considerado indiscutível, pronto e acabado e o material de ensino é o mesmo em qualquer país, devendo ser repassado e memorizado para ser avaliado (em arguições orais, de preferência). A ação docente consiste em transmitir esse conteúdo indiscutível, através da exposição laula expositiva - quase palestra) seguida de exercícios a serem resolvidos pelos alunos e a avaliação se torna um mecanismo de controle rígido e preestabelecido. Para ser professor é preciso ter vocação e conhecimento dos conteúdos a serem ensinados. A capacitação de professores se faz com ênfase no conhecimento da área ou da disciplina, predominando a preleção pelo 
docente, a memorização, a avaliação classificatória, a emulação (imitação na ausência do modelo) e o castigo (MARTINES, 2005).

\subsection{0 racionalismo técnico-científico}

Embora as origens do currículo escolar remontem ao século XVI, a teorização curricular - ou o discurso científico sobre o currículo surgiu somente na década de 1920 nos Estados Unidos, quando começou a produção de textos de educadores insatisfeitos com o modelo de escola existente, construído pela burguesia dos países capitalistas. Essa crítica à escola tradicional e aos seus métodos esboça uma nova maneira de ver a educação e ensaia algumas experiências inovadoras com o fim de implantá-las extensivamente nos sistemas escolares (MARTINES, 2005).

Enquanto na pedagogia tradicional predominavam os pressupostos disciplinar e liberal, dando ênfase aos produtos da ciência (suas leis explicativas do real), os currículos da Escola Nova valorizavam muito mais a produção do conhecimento científico do que seus produtos, colocando o método de projeto e a pesquisa como métodos de ensino.

A teorização em torno do currículo começou com um discurso pragmático, emancipatório e democratizador, mas, converteu-se em um discurso cientificista e tecnicista em meados do século $X X$, devido às interações entre a Escola Nova com ênfase na experiência da criança e em seus interesses e um grupo que advogava a preparação da criança para a vida adulta e o mundo do trabalho. Nesse período, a sociedade norteamericana vivia sua primeira revolução científica e tecnológica fazendo surgir a concepção moderna de currículo, apoiada na aplicação dos princípios da administração científica à escola e ao currículo, através da padronização e predeterminação do produto, inaugurando uma teorização em torno de um modelo racional de administração científica em educação (MARTINES, 2005).

O trabalho pedagógico com crianças portadoras de deficiências, a avaliação dos treinamentos de soldados na $2^{a}$. Guerra Mundial, a 
controvérsia entre os defensores do currículo tradicional e os do currículo progressista (baseados na proposta de John Dewey) e as pesquisas de avaliação de currículos levaram ao modelo de currículo por objetivos, surgindo uma grande preocupação com a definição prévia de objetivos e de como medir o alcance destes objetivos após a aplicação de um programa educacional.

Assim, no período de 1950 a 1970, no qual a sociedade americana passou por sucessivas crises (perda da corrida armamentista para os russos, guerra fria, problemas sociais profundos como racismo, desemprego, violência, guerra com o Vietnã, contracultura, entre outros), ocorreram mudanças nos paradigmas científicos e na educação, culminando com o aparecimento de três grandes tendências. Por um lado, o discurso taylorista da eficácia, por outro, o discurso escolanovista da liberdade nas escolas e até uma corrente utópica que defendia o fim das escolas ou a desescolarização da sociedade.

Uma área da Psicologia que se desenvolveu muito neste período foi a Psicometria, que voltou sua atenção para a criação de testes e instrumentos de medidas de inteligência, de aptidões e atitudes, de desempenho, contribuindo para a construção do modelo de currículo por objetivos, prescritivo e técnico-linear. Este modelo de currículo prevê o estabelecimento prévio ao ensino de objetivos educacionais a serem atingidos e critérios de avaliação para verificar se os objetivos foram atingidos ou não (MARTINES, 2005).

No auge da expansão desse movimento para fora dos EUA, O Brasil vivia o período de ditadura militar que promoveu uma grande expansão do sistema escolar (primário e ginasial) e a reforma universitária através da Lei 5.540/68, a qual ampliou a divisão do conhecimento em especialidades promovida pela ciência, o que causou uma forte fragmentação da estrutura de poder nas universidades brasileiras.

A grande demanda por formação de professores para atender à expansão da educação básica levou à criação de licenciaturas curtas e de 
faculdades particulares (as quais passaram a ter como principal missão formar rapidamente um grande contingente de professores para o ginasial) e criação de novas Escolas Normais, responsáveis pela formação de professores para o primário (segundo ao quinto ano do atual Ensino Fundamental). Logo a seguir, se regulamentou as licenciaturas plenas que complementavam as licenciaturas curtas com mais um ano de formação em uma especialidade para ensinar no Ensino Colegial (atual Ensino Médio).

Estas mudanças acabaram consolidando o que ficou conhecido como Modelo 3+1 voltado para formação do professor técnico-científico, com três anos de formação em uma especialidade (Química, Física, Biologia ou Matemática) seguido de um ano de estudos em disciplinas pedagógicas e prática de ensino com estágio na escola.

Neste modelo, foram experimentados currículos alternativos que acabaram sofisticando o currículo tradicional com a grande expansão da teorização curricular voltada para o desenvolvimento destes currículos, fazendo surgir o chamado Currículo por objetivos: prescrito por especialistas externos à escola (técnicos da Psicologia do Desenvolvimento, das especialidades científicas, da Psicometria) e mantendo o escalonamento dos conteúdos de forma linear.

A consequência dessas mudanças resultou em uma grande separação entre: teoria e prática, conhecimento pedagógico e conhecimento específico, ensino e pesquisa, bacharelado e licenciatura e o professor passou a ser visto como um técnico que precisa ser equipado com um kit de ferramentas para solucionar os problemas de sua profissão.

\subsection{O modelo do racionalismo crítico}

A partir de 1960 os países do ocidente passaram por um período de grandes agitações e transformações e, no momento mesmo em que os currículos técnico-científico, prescritivo e burocrático se consolidavam como hegemônico em vários países, iniciou-se também um movimento de renovação em vários locais. Voltou-se a enfatizar os fins da educação (ao 
invés dos meios - objetivos instrucionais, técnicas de ensino e de avaliação) e a prática dos professores, uma vez que estes ficaram em segundo plano na concepção técnico-científica e passaram a ser meros executores de currículos produzidos pelos especialistas; esperava-se que recorrecem às técnicas pedagógicas para solucionar os problemas da docência.

Passou-se também a criticar a biologização e a psicologização dos fenômenos sociais (MOYSÉs; COLLARES, 1993; PATTO, 1996; MARTINES, 2001). Esta segunda onda de reação à teorização e prática do currículo foi mais generalizada que a anterior (início do século XX), podendo ser identificados vários focos de teorização crítica e Paulo Freire é o mais conhecido no Brasil; na Inglaterra se destacaram Stenhouse, Elliott, MacDonald, Young, Bernstein; na América do Norte, Bowles e Gintis, Apple, Giroux, Pinar, Grumet e Greene, entre outros (MARTINES, 2005).

Enquanto os modelos tradicional (currículo acadêmico) e tecnicista (currículo por objetivos) se restringem ao como fazer o currículo, as teorias críticas colocam em questão os pressupostos dos presentes arranjos sociais e educacionais, desconfiando do status quo e responsabilizando-o pelas desigualdades e injustiças sociais. Enquanto as teorias tradicionais sobre currículo e educação em geral, especialmente o funcionalismo norteamericano, eram teorias de aceitação, ajuste e adaptação, as teorias críticas buscam "[...] desenvolver conceitos que permitam compreender 0 que o currículo faz" (SILVA, 2000, p. 27).

Em nosso país, a década de 1980 foi marcada por ardoroso debate em torno das questões de conteúdo curricular entre aqueles mais comprometidos com as camadas mais pobres da população. Embora todos concordassem com a importância da escola para estas camadas, havia grande discordância quanto aos conteúdos a serem ensinados. Alguns esforços foram feitos tanto por educadores da educação popular como da pedagogia dos conteúdos na aplicação de suas ideias em processos de renovação curricular em diferentes sistemas escolares do Brasil, mas estas 
experiências permanecem insuficientemente estudadas, segundo Moreira (2001).

Nos EUA, William Pinar e seu grupo fortaleceram a onda de reação à escolarização tecnicista e prescritiva organizando a I Conferência sobre Currículo na Universidade de Rochester, Nova Iorque, em 1973. Este movimento ficou conhecido como Reconceitualização do Currículo, mas acabou dissolvido no pós-estruturalismo, no feminismo, nos Estudos Culturais, nas concepções fenomenológicas, hermenêuticas e autobiográficas de crítica aos modelos tradicionais de escolarização e de currículo. $\mathrm{Na}$ Inglaterra, diferentemente do que ocorria nos Estados Unidos, a crítica do currículo se dava a partir da Sociologia, principalmente através de Young, Bourdieu e Bernstein, que desenvolveram uma crítica que ficou conhecida como "A Nova Sociologia da Educação" (NSE) e seu programa se centra na crítica sociológica e histórica dos currículos existentes (MARTINES, 2005).

Outra linha de pesquisas que contribuiu para o questionamento do currículo técnico-científico e prescritivo, sem dúvida foi na área de avaliação educacional, desenvolvida por pesquisadores que ficaram conhecidos como Terceira e Quarta Gerações de Avaliadores. Estas foram mais longe que as gerações que as antecederam e surgiu pelas limitações da fase anterior. Criticou-se que havia uma preocupação excessiva com os objetivos, sendo que muitos deles nem sempre eram claros e visíveis e também, porque muitos nem eram previsíveis antes da aplicação de um determinado programa. Isto fazia com que o processo avaliativo ficasse emperrado, tornando muitas avaliações inúteis e irrelevantes, inclusive avaliações do desempenho escolar (PENA-FIRME,1994).

Um ponto digno de menção nessa geração é a preocupação com o mérito e a relevância, características essenciais no juízo de valor: a preocupação com o mérito diz respeito às qualidades intrínsecas do objeto que está sendo avaliado e a preocupação com a relevância, aponta para seus resultados, para o impacto ou influência, seu valor extrínseco ou contextual. À medida que a avaliação educacional evoluía, alguns 
problemas foram sendo identificados e para tentar superar as falhas quanto à participação e pluralismo de valores, no início dos anos noventa esta área incorporou a ideia de consenso a ser buscado entre pessoas com interesses e valores diferentes, respeitando-se os dissensos identificados. Tudo isso influenciou fortemente o desenvolvimento da pesquisa qualitativa em educação. Entretanto, todos os recursos já desenvolvidos nas gerações anteriores são aproveitados, ao máximo, após criteriosa análise, mas vai além, incluindo até recursos das artes, como no caso da avaliação por meio de portifólios pessoais por professores, inspirados na avaliação da produção artística.

Assim, o modelo do racionalismo crítico tem seu foco na transformação da sociedade, baseado principalmente na teoria marxista e neomarxista, com propostas que vão da desescolarização da sociedade à desconstrução do conhecimento escolar e científico. Quanto à identidade docente vai se consolidando a concepção do professor como um trabalhador da educação.

\subsection{A racionalidade prática e os currículos inovadores}

Outra corrente de teorização que criticou e reagiu ao currículo técnico-prescritivo afastando-se da Psicologia vem sendo denominada de racionalismo prático. Dois nomes que se destacam como pioneiros nesta área são os de Schwab e Stenhouse, que na década de 1960 passaram a defender a necessidade dos professores serem colocados no centro do processo de renovação do currículo e "[...] concebidos como realizadores, fazendo julgamentos baseados em seu próprio conhecimento e experiência e nas demandas das situações práticas" (PEREIRA; ZEICHNER, 2002, p. 25).

O modelo da racionalidade prática é sintetizado por Pereira como aquele que entende a educação como um processo complexo ou "[...] uma atividade modificada à luz de circunstâncias, as quais somente podem ser 'controladas' por meio de decisões sábias feitas pelos profissionais, ou seja, por meio de sua deliberação sobre a prática". Além do conhecimento 
de técnicas de ensino e de avaliação, o conhecimento profissional docente está sujeito à incerteza e complexidade da prática, exigindo "[...] uma leitura sensível das mudanças sutis e da reação de outros participantes desse processo" (PEREIRA; ZEICHNER, 2002, p. 24-5).

Nesta abordagem há uma valorização do pensamento do professor, que é visto como um pesquisador de sua própria prática e o currículo passa a ser o elemento essencial da formação profissional do professor, uma vez que não se limita às especificações que precisam ser colocadas em prática, mas "[...] necessita ser sempre interpretado, adaptado e, inclusive, (re)criado por meio do ensino que o professor realiza" (CONTRERAS, 2002, p. 118).

O movimento inicial levou à proposição de currículos inovadores experimentados e investigados pelos professores em sua prática docente, mas foi criticado por nutrir certo desprezo pela teoria e por sua dificuldade de se generalizar em sistemas educacionais mais amplos que as escolas nas quais foram experimentados (GOODSON, 1995).

A identidade docente se amplia nesta perspectiva: o professor é visto como artesão que se utiliza principalmente da técnica de bricolagem e/ou como professor pesquisador e a pesquisa-ação é a técnica privilegiada para tal, com foco na prática do professor, em contextos de mudanças curriculares, tendo como finalidade tanto o aperfeiçoamento de currículos (tradicional ou alternativos) como o desenvolvimento profissional do professor, considerado um profissional prático-reflexivo.

\subsection{Modelo emergente}

A partir da década de 1990, o Ministério da Educação do Brasil (MEC) tem divulgado diretrizes para a elaboração de currículos no ensino superior, incluindo os Referenciais para a Formação de Professores, que vieram substituir os chamados currículos mínimos para os cursos de graduação. Também criou os Parâmetros Curriculares Nacionais (PCN) para a Educação Básica (Ensino Fundamental, Ensino Médio e Tecnológico) (BRASIL, 1997; 1998; 
1999) e publicou as Diretrizes para organização curricular de cursos diveros, especialmente para formação de professores para a educação básica.

Podemos dizer que estes documentos se inserem em um modelo que chamei de emergente (MARTINES, 2005), buscando aproveitar os pontos positivos de modelos anteriormente discutidos, evidenciados pela crítica própria do desenvolvimento científico. Este modelo emergente entende a realidade social, na qual se inserem as escolas e a prática docente, como historicamente construída, situada, complexa e em processo permanente de transformação e que o conhecimento está distribuído dentro de sistemas, em diferentes níveis de complexidade e de organização (currículo como processo social).

Neste modelo, a prática docente vem deixando de ser vista como sacerdócio ou apostolado (uma vocação) ou como mera aplicação de técnicas e o professor vai conquistando o status de profissional, que necessita cada vez mais de alta qualificação para exercer com responsabilidade e autonomia sua prática de formação de novas gerações, numa sociedade complexa, mutante, contraditória (NÓVOA, 1992; PAQUAY et al, 2001; DEMO, 2002). Fala-se cada vez mais na necessidade de formação continuada de professores e professoras para o desenvolvimento profissional, relacionando teoria com a prática, através da reflexão e/ou da pesquisa-ação (professor-pesquisador). Há toda uma valorização da história de vida de professores, da necessidade de reflexão sobre sua prática, sobre os conteúdos e técnicas adotadas, sobre os fins da educação e dos objetivos propostos.

As novas diretrizes para formação de professores no Brasil incorporam a maioria desses conceitos, como se pode ver nos Pareceres do Conselho Nacional de Educação (CNE) e Resoluções (BRASIL, 2001; 2002, 2002b; 2015a; $2015 b$. Outro ponto relacionado com a formação do professor reflexivo que se destaca nas diretrizes é a tentativa de resgatar a articulação teoria-prática que em dado momento histórico de nossos cursos superiores se desfez. Como já vimos anteriormente, a reforma universitária que se instalou no Brasil 
durante a ditadura militar criou as licenciaturas como complementação pedagógica dos cursos de bacharelado ou de licenciaturas curtas, num modelo que ficou conhecido como $3+1$, isto é, os alunos passam três anos estudando teorias de uma área de conhecimento e da educação, ficando o contato com a prática nas escolas para o último ano. Nas diretrizes para formação docente para a educação básica a prática de ensino deve ocorrer ao longo de todo o curso, à medida que se desenvolvem as disciplinas específicas da área e não mais no último ano da licenciatura.

Outra diretriz presente em todos os documentos oficiais que orientam a reforma educacional em curso no Brasil se refere à contextualização dos conteúdos curriculares, uma vez que, tanto os historiadores da ciência como do currículo defendem que, à medida que o conhecimento científico foi se fragmentando cada vez mais em função da especialização crescente da ciência moderna, ele foi também se tornando cada vez mais descontextualizado e desencarnado. Isto é, foi se distanciando dos problemas existenciais e práticos, pois os problemas científicos passaram a ser definidos pelos paradigmas disciplinares. Também foram sofrendo influências outras, como por exemplo, das profissões que foram surgindo com o desenvolvimento científico-tecnológico da sociedade industrial. Esta é também uma bandeira do currículo integrado defendido por Dewey e expandido pelos construtivistas e pela perspectiva crítica: a valorização de um currículo voltado para os interesses e experiências dos alunos e para aprendizagens significativas que enfatizem a contextualização ou a aproximação dos conteúdos escolares dos saberes cotidianos, situados.

A formação de professores para o ensino de ciências vem sofrendo influência de todos estes modelos ou paradigmas, ao longo do tempo e no momento encontramos práticas que refletem tradições, mas também encontramos inovações em curso.

\section{CONSIDERAÇÕES FINAIS}

O modelo do Racionalismo Acadêmico ainda predomina nos currículos escolares de todos os níveis de educação em nosso país, com 
influências nos cursos de formação de professores de ciências e biologia, resultando no chamado Currículo tradicional - currículo baseado nas disciplinas acadêmicas, na avaliação por exames e organização em salas de aulas. A capacitação de professores se faz com ênfase no conhecimento da área ou da disciplina.

O Racionalismo Técnico que passou a predominar na ciência e foi transferido para a economia e para a educação, aprofundou a ênfase disciplinar e passou a influenciar a formação de professores como técnicos que precisam dominar uma tecnologia educacional cada vez mais sofisticada para execução de tarefas burocráticas de execução de currículos prescritos por especialistas externos à escola, com definição de objetivos e avaliação para verificação da consecução de objetivos previstos.

A Teorização Crítica propõe desde a substituição da escola por outras instituições até currículos alternativos para vários grupos sociais, geralmente marginalizados. A formação de professores se dá com ênfase em conceitos como Historicização/desconstrução/desnaturalização. Atualmente, este modelo se encontra numa crise teórico-prática, com pouca contribuição efetiva para a melhoria dos sistemas escolares, especialmente na Amèrica Latina, segundo Saviani (2002). Já o Racionalismo Prático se constitui num modelo centrado em currículos inovadores e no desenvolvimento profissional do professor baseado na pesquisa-ação sobre inovações curriculares, na reflexão, no conceito do professor pesquisador e vem influenciando a pesquisa avaliativa emancipatória para desenvolvimento profissional e aperfeiçoamento do currículo.

Numa evolução da teorização crítica e da racionalidade prática, entendo que emerge um modelo que valoriza o pensamento do professor, o conhecimento sistêmico ou distribuído e a complexidade da prática docente. Daí, a necessidade de formação continuada de professores e professoras para o desenvolvimento profissional, relacionando teoria com a prática, através da reflexão e/ou da pesquisa-ação (professor-pesquisador), 
com valorização da história de vida de professores e de instituições escolares.

Entretanto, em nosso país o ensino e a aprendizagem de ciências e biologia ainda enfrentam muitos problemas e diversas forças se confrontam no sentido de manter o status quo. O modelo jesuítico de instituição escolar associado com a racionalidade acadêmica ainda é muito forte nos currículos de formação de professores, com influências do modelo de racionalidade técnica variando em função de maior ou menor grau de penetração das teorias críticas e pós-críticas. No Brasil, a Pedagogia Libertadora (iniciada por Paulo Freire) e a Pedagogia Histórico-Crítica ou de Conteúdos (proposta por Dermeval Saviani) tem inspirado a elaboração e experimentação de currículos alternativos em vários locais, mas ainda carecem de estudos sobre seus resultados.

Acompanhando NUÑEZ e RAMALHO3 entendemos a profissionalização como um processo de construção da identidade docente pelos professores, na qualidade de um grupo que exerce uma atividade social específica, a qual se define, em parte, por características objetivas, mas, também envolvem a subjetividade, pois é também uma identidade, uma forma de representar a profissão, as suas responsabilidades, a sua formação contínua e a sua relação diversa com outros profissionais. Como outros autores, vemos a profissionalização como um movimento ideológico (já que repousam em novas ideias ou representações do ensino, do saber do professor e no interior do sistema educativo), mas é também político e econômico por induzir novos modos de gestão do trabalho docente e de relações de poder entre os grupos (dentro e fora da instituição escolar).

Assim, ao longo da história, a figura do professor vem sendo representada de várias formas, passando da imagem do mestre/artesão para a da vocação, o professor técnico-científico até se chegar na

\footnotetext{
3 NUÑEZ, I. B.; RAMALHO, B. L. As representações de professores sobre a docência como profissão: uma questão a se pensar nos projetos formativos. Texto em PDF, sem data. Disponível em http://www.comperve.ufrn.br/conteudo/observatorio/uploads/publicacoes/ artigos05022013080543.pdf. Acessado em 15/04/2017.
} 
atualidade à imagem do professor profissional com toda a complexidade que isto representa.

Embora as novas diretrizes para formação de professores no Brasil incorporem a maioria dos conceitos presentes na abordagem emergente para formação de professores, sua implementação nos currículos das licenciaturas da área se torna um desafio para as instituições formadoras. A criação de uma nova institucionalidade apoiada nos princípios de funcionamento em rede das universidades públicas e das escolas e outras instituições que tenham interesses e recursos para tal, aproveitando-se experiências bem sucedidas neste sentido (pois elas existem) poderão facilitar esta tarefa de reconstrução dos currículos e práticas de formação docente em tempos de incertezas, buscando o desenvolvimento profissional dos professores e de currículos que atendam as necessidades de escolarização de nossas comunidades, conforme propõe Pimentel (1993, p. 33) e com quem concordamos: para uma prática de "conhecimento prudente para uma vida decente".

\section{REFERÊNCIAS}

BRASIL, MEC / Secretaria de Educação Fundamental. Parâmetros Curriculares Nacionais. Primeiro e segundo ciclos do ensino fundamental. Brasília, 1997.

BRASIL, MEC / Secretaria de Educação Fundamental. Parâmetros Curriculares Nacionais. Terceiro e quarto ciclos do ensino fundamental. Brasília, 1998.

BRASIL, MEC / Secretaria de Educação Média e Tecnológica. Parâmetros Curriculares Nacionais. Ensino Médio. Brasília, 1999.

BRASIL, MEC / Conselho Nacional de Educação. Parecer 09/2001 do CNE/CP. Diretrizes Curriculares Nacionais para a Formação de Professores da Educação Básica, em nível superior, curso de licenciatura, de graduação plena. Brasília, 08 de maio de 2001.

BRASIL, MEC / Conselho Nacional de Educação. Resolução 1 / 2002 do CNE / CP. Institui Diretrizes Curriculares Nacionais para a Formação de Professores da Educação Básica, em nível superior, curso de licenciatura, de graduação plena. Brasília, 18 de fevereiro de 2002a.

BRASIL, MEC / Conselho Nacional de Educação. Resolução 2 / 2002 do CNE / CP Institui a duração e carga horária dos cursos de licenciatura, de 
graduação plena, de formação de professores da Educação Básica em nível superior. Brasília, 19 de fevereiro de 2002b.

BRASIL, MEC / Conselho Nacional de Educação. Parecer n. 2 /2015. Diretrizes Curriculares Nacionais para a Formação Inicial e Continuada dos Profissionais do Magistério da Educação Básica. Brasília, 2015a. Disponível em: http://portal.mec.gov.br/index.php?option=com_docman\&view=download \&alias=17625-parecer-cne-cp-2-2015-aprovado-9-junho-2015\&category _slug=junho-2015-pdf\&ltemid=30192. Acesso em 10 de março de 2016.

BRASIL, MEC / Conselho Nacional de Educação. Resolução n. 2 de $1^{\circ}$ de julho de 2015. Define as Diretrizes Curriculares Nacionais para a formação inicial em nível superior (cursos de licenciatura, cursos de formação pedagógica para graduados e cursos de segunda licenciatura) e para a formação continuada. Brasília, 2015b. Disponível em: http://portal.mec.gov.br/index.php?option=com_docman\&view=download \&alias=17719-res-cne-cp-002-03072015\&category_slug=julho-2015pdf\&ltemid=30192. Acesso em 15 de março de 2016.

BRUNER, J. En busca de la mente. Ensayos de autobiografía. México: Fondo de Cultura Económica. Linaza, 1985.

CONTRERAS, J. A autonomia dos professores. São Paulo: Cortez, 2002

DEMO, P. Complexidade e aprendizagem - a dinâmica não linear do conhecimento. SP: Ed. Atlas, 2002.

GOODSON, I. F. 2 ed. Currículo: teoria e história. Petrópolis: Vozes, 1995.

HUBERMAN, M. O ciclo de vida profissional dos professores. In NÓVOA, A. (org.). Vidas de professores. Porto / Portugal: Porto Ed., 1995. Pp. 31-61

MARTINES, E. A. L. M. Análise dos Parâmetros Curriculares Nacionais na perspectiva da avaliação de currículos e da formação de professores de Ciências Naturais. Dissertação de Mestrado. Programa de Psicologia Escolar e do Desenvolvimento Humano. Instituto de Psicologia. Universidade de São Paulo. São Paulo, 2000. $123 \mathrm{f}$.

MARTINES, E. A. L. M. A biologização / naturalização de problemas sociais e a queixa escolar. In PARMEGIANI, T. e GURGEL, N. (Orgs.). Um olhar para o letramento - rompendo silêncios e construindo histórias. Porto Velho: EDUFRO, 2001. pp. 171-208.

MARTINES, E. A. L. M. O currículo possível na educação superior: estudo sobre o curso de Ciências Biológicas em uma universidade amazônica. Tese de Doutorado. Programa de Psicologia Escolar e do Desenvolvimento Humano. Instituto de Psicologia. Universidade de São Paulo. São Paulo, 2005. 332f. Disponível em http://www.teses.usp.br/teses/disponiveis/47/47131/tde-22032007-163140/ptbr.php.

MARTINES, E. A. L. M. Pressupostos teórico-práticos de currículos de formação do professor de ciências e biologia. In AMARAL, N. F. G.; BRASILEIRO, T. S. A. 
Formação docente e estratégias de integração universidade/escola nos cursos de licenciatura. Voll. Porto Velho: EDUFRO, 2008. pp. 57-67.

MARTINES, E. A. L. M. SOUZA, L. S.; ALMEIDA, A. D.; OlIVEIRA, A. C. G. Formação docente para uma escola igualitária: o caso do ensino de ciências. In FRANCISCO JUNIOR, W. E.; OLIVEIRA, A. C. G. de; MARTINES, E. A. L. M. Educação em ciências em Rondônia: pesquisas e interações universidade-escola. Porto Velho: EDUFRO, 2010. pp. 111-123.

MARTINES, E. A. L. M. Relatório Técnico Projeto Um Computador por Aluno (UCA) - Estudo de caso da implantação do projeto UCA em Rondônia. Porto Velho, 2014.

MOREIRA, A. F. A crise da teoria curricular crítica. In COSTA, M. V. O currículo nos limiares do contemporâneo. 2ed. Rio de Janeiro: DP\&A Ed., 2001. pp. 2040.

MOYSÉS, M. A. A; COLLARES, C. A. L. Sobre alguns preconceitos no cotidiano escolar. In Alfabetização: passado, presente e futuro. São Paulo: FDE, 1993. pp. 9-25.

NÓVOA, A. (Org.). Os professores e a sua formação. Lisboa / Portugal: Publicações Dom Quixote, 1995.

PAQUAY, L.; PERRENOUD, P.; ALTET, M.; CHARTIER, E. Formando professores profissionais - Quais estratégias? Quais competências? 2ed. Porto Alegre: ArtMed., 2001.

PATTO, M. H. S. A produção do fracasso escolar. SP: T.A. Queiroz, 1996.

PENNA-FIRME, T. Tendências e tendenciosidades. Ensaio, Vol.1, n.2, 1994.

PEREIRA, J. E. D.; ZEICHNER, K. M. (Orgs.). A pesquisa na formação e no trabalho docente. Belo Horizonte: Autêntica, 2002.

PIMENTA, S. G.; ANASTASIOU, L. G. C. Docência no ensino superior. Vol.1. SP: Cortez, 2002.

PIMENTEL, M. G. O professor em construção. 9ed. Campinas / SP: Papirus, 2003.

RAMALHO, B. L.; NUÑEZ, I. B.; GAUTHIER, C. Formar o professor: profissionalizar o ensino- perspectivas e desafios. Porto Alegre: Sulinas, 2004.

SAVIANI, D. Escola e democracia. 35ed. Campinas / SP: Ed. Aut. Associados, 2002.

SILVA, T. T. Teorias do currículo - uma introdução crítica. Porto: Porto Editora, 2000. $158 \mathrm{p}$. 